\title{
Marked Variation in Serum Chromogranin A Levels in a Patient on Chronic Omeprazole Therapy
}

\author{
Theresa Ratajczak ${ }^{\mathrm{a}}$, Ankur Gupta ${ }^{\mathrm{a}, \mathrm{b}}$
}

\begin{abstract}
Serum chromogranin $\mathrm{A}(\mathrm{Cg} \mathrm{A})$ is used as a standard marker in the diagnosis of neuroendocrine tumors. We report a case with wide fluctuation (more than 10-fold) in serum CgA levels in a patient on chronic omeprazole therapy. A 67-year-old woman with hypothyroidism presented for evaluation of facial flushing for 1 year. Flushing had increased in intensity over the past several months without any provocative factors. She denied any diarrhea, wheezing, headache, palpitations or facial erythema. Her home medications were aspirin, omeprazole, levothyroxine, and raloxifene. The patient reported no improvement in flushing on stopping raloxifene. Physical exam was unremarkable. On blood testing, she was noted to have mildly elevated serum CgA of $18.8 \mathrm{ng} /$ $\mathrm{mL}$ (range 1.9 - $15 \mathrm{ng} / \mathrm{mL}$ ). Other endocrine tests including serum tryptase, 24-hour urine N-methylhistamine, 24-hour urine 5-hydroxyindoleacetic acid, metanephrines, catecholamines, and serum calcitonin were unremarkable. Serum CgA was repeated because of her continued symptoms. Repeat blood test showed markedly increased $\mathrm{CgA}$ value $(128 \mathrm{ng} / \mathrm{mL})$. She underwent a CT chest/abdomen/pelvis and octreotide scan. The octreotide scan showed uptake in the right axillary and subcarinal regions. She subsequently underwent endoscopic bronchial ultrasound and mediastinal biopsy of two lymph nodes. Biopsy was negative for any pathological process. PET scan was done to rule out occult malignancies and was negative. Echocardiogram was normal. She was also seen by neurology with unremarkable workup. $\mathrm{CgA}$ levels were repeated over a course of three months and levels varied from 126 to $182 \mathrm{ng} / \mathrm{mL}$. She was asked to hold omeprazole for 2 weeks and CgA levels dropped to $24 \mathrm{ng} / \mathrm{mL}$. The patient resumed omeprazole due to worsening reflux. Repeat $\mathrm{CgA}$ level three months later on omeprazole was $18 \mathrm{ng} / \mathrm{mL}$. Venlafaxine and paroxetine were tried for flushing but she could not tolerate these due to side effects. It had been previously established that medications which stimulate neuroendocrine cells, in particular proton pump inhibitors (PPI) could lead to falsely elevated $\mathrm{CgA}$ levels. The interesting aspect in this case
\end{abstract}

Manuscript accepted for publication April 15, 2015

aDepartment of Internal Medicine, Boonshoft School of Medicine, Wright State University, Dayton, OH, USA

${ }^{b}$ Corresponding Author: Ankur Gupta, Department of Internal Medicine, Boonshoft School of Medicine, Wright State University, Dayton, OH, USA. Email: ankur.gupta@wright.edu

doi: http://dx.doi.org/10.14740/jmc2135w is increase in $\mathrm{CgA}$ more than 10 -fold and the marked variation in $\mathrm{CgA}$ levels while on omeprazole $(18-182 \mathrm{ng} / \mathrm{mL})$. There is marked variability in serum CgA levels in presence of a PPI as seen in our case. Clinicians should consider repeat testing of CgA levels in setting of abnormal values and also consider stopping contributing medications before testing and making important clinical decisions.

Keywords: Chromogranin A; Proton pump inhibitors; Variation

\section{Introduction}

Chromogranin $\mathrm{A}(\mathrm{CgA})$ is a secretory protein used as a standard marker in immunohistochemical diagnosis of neuroendocrine tumors [1]. We report a case with wide fluctuation (more than 10-fold) in serum CgA levels in a patient on chronic omeprazole therapy.

\section{Case Report}

A 67-year-old woman with past medical history significant for hyperlipidemia, hypothyroidism, and osteoarthritis presented for evaluation of facial flushing for 1 year. Flushing had increased in intensity over the past several months and had been occurring up to 10 times daily without any provocative factors. She denied diarrhea, wheezing, headache, palpitations or facial erythema. Her home medications were aspirin, omeprazole, levothyroxine, and raloxifene. The patient reported no improvement in flushing on stopping raloxifene.

Physical examination was unremarkable with no erythema, lymphadenopathy, wheezing or murmurs. On blood testing, she was noted to have mildly elevated serum $\mathrm{CgA}$ of 18.8 $\mathrm{ng} / \mathrm{mL}$ (range 1.9 - $15 \mathrm{ng} / \mathrm{mL}$ ). Electro-chemiluminescence (ECLIA) method was used for the testing. Other endocrine tests including serum tryptase, 24-h urine N-methyl histamine, 24-h urine 5-hydroxyindoleacetic acid (5-HIAA), metanephrines, catecholamines, serum calcitonin, and serum carcinoembryonic antigen were unremarkable.

She returned for a follow-up visit a month later due to persistent symptoms of flushing. Serum $\mathrm{CgA}$ was repeated and markedly increased from 18.8 to $128 \mathrm{ng} / \mathrm{mL}$. She underwent a computed tomography (CT) scan chest/abdomen/pelvis and an 
Table 1. Chromogranin A Levels in Relation to Omeprazole Therapy

\begin{tabular}{lll}
\hline Date of lab collection & Serum chromogranin A level in $\mathbf{n g} \mathbf{m L}$ & Omeprazole therapy \\
\hline December 2013 & 18 & On omeprazole \\
\hline January 2014 & 126 & On omeprazole \\
\hline February 2014 & 128 & On omeprazole \\
\hline March 2014 & 182 & On omeprazole \\
April 2014 & 126 & On omeprazole \\
May 2014 & 138 & On omeprazole \\
June 2014 & 24 & 2 weeks off omeprazole \\
September 2014 & 18 & On omeprazole \\
\hline
\end{tabular}

octreotide scan. The octreotide scan showed uptake in the right axillary and subcarinal regions. She subsequently underwent endoscopic bronchial ultrasound and mediastinal biopsy of two lymph nodes in the area of uptake on the octreotide scan. Biopsy was negative for any pathological process. Echocardiogram was normal. PET scan was done to rule out occult malignancies and was negative. She was also seen by neurology with an unremarkable workup.

The patient was found to have persistently elevated serum $\mathrm{CgA}$ levels over a period of several months that ranged from 126 to $182 \mathrm{ng} / \mathrm{mL}$. She continued to have flushing. After a comprehensive workup, she underwent a trial discontinuation of her proton pump inhibitor (PPI). Her repeat serum CgA levels after two weeks of PPI cessation dropped to $24 \mathrm{ng} / \mathrm{mL}$. The patient resumed omeprazole due to worsening gastroesophageal reflux. She continued to have symptoms. Venlafaxine and paroxetine were tried but she could not tolerate these medications due to side effects. Serum $\mathrm{CgA}$ level three months later on omeprazole was noted to be $18 \mathrm{ng} / \mathrm{mL}$ (Table 1 and Fig. 1).

\section{Discussion}

The differential diagnosis of flushing is broad and includes physiological causes, menopause, medications, food, alcohol or skin conditions such as rosacea. Additionally, the more serious medical conditions include carcinoid syndrome, mastocytosis or medullary carcinoma of the thyroid, etc. [2].

Serum CgA and urine 5-hydroxyindolacetic acid are considered the most useful biochemical markers in evaluation of carcinoid tumors in diagnosis and follow-up after treatment [1]. The number of patients using acid suppressive medications has increased significantly since their introduction in the 1980s, prescription as well as over the counter [3]. It had been previously established that medications which stimulate neuroendocrine cells, particularly PPIs could lead to falsely elevated $\mathrm{CgA}$ levels [4]. The mechanism of $\mathrm{CgA}$ elevation is unclear, with some studies suggesting that gastric acid inhibition causes proliferation of the enterochromaffin cells and elevated release of gastrin which in turn causes elevated CgA levels [5].

The interesting aspect in this case is the magnitude of increase in CgA levels (more than 10-fold) and the marked variation in serum CgA levels while on omeprazole (18 - $182 \mathrm{ng} /$ $\mathrm{mL}$ ). Braga and group looked at biological variation of serum $\mathrm{CgA}$ in 22 healthy volunteers (men and women) not taking any medications every two weeks for two months. The study showed variation of CgA (less than five-fold) on repeated testing [6]. In this patient who was taking a PPI, the range of re-

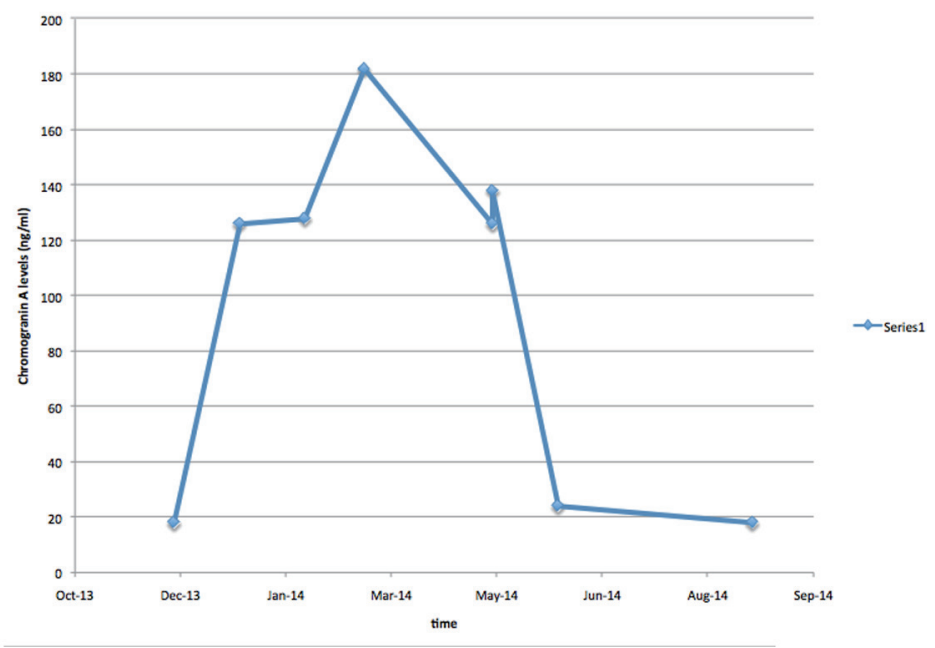

Figure 1. Level of chromogranin A measured over a course of 10 months. 
sults was more widespread.

\section{Conclusion}

There is marked variability in serum CgA levels in presence of proton pump inhibitors as seen in our case. Serum CgA levels are also variable in absence of proton pump inhibitors. Clinicians should consider repeat testing of serum $\mathrm{CgA}$ levels in setting of abnormal values and also consider stopping contributing medications before testing and making important clinical decisions.

\section{Acknowledgement}

We would like to also acknowledge the assistance of Dr Ronald J. Markert, Ph.D., Vice Chairman for Research, Department of Internal Medicine, Wright State University Boonshoft School of Medicine, Dayton Ohio, for his comments and critical review of the manuscript.

\section{Conflict of Interest}

The authors of this article have no conflict of interest to declare.

\section{References}

1. Giusti M, Sidoti M, Augeri C, Rabitti C, Minuto F. Effect of short-term treatment with low dosages of the protonpump inhibitor omeprazole on serum chromogranin A levels in man. Eur J Endocrinol. 2004;150(3):299-303.

2. http://www.clevelandclinicmeded.com/medicalpubs/diseasemanagement/endocrinology/flushing.

3. Raines D, Chester M, Diebold AE, Mamikunian P, Anthony CT, Mamikunian G, Woltering EA. A prospective evaluation of the effect of chronic proton pump inhibitor use on plasma biomarker levels in humans. Pancreas. 2012;41(4):508-511.

4. Korse CM, Muller M, Taal BG. Discontinuation of proton pump inhibitors during assessment of chromogranin A levels in patients with neuroendocrine tumours. Br J Cancer. 2011;105(8):1173-1175.

5. Sanduleanu S, Stridsberg M, Jonkers D, Hameeteman W, Biemond I, Lundqvist G, Lamers C, et al. Serum gastrin and chromogranin A during medium- and long-term acid suppressive therapy: a case-control study. Aliment Pharmacol Ther. 1999;13(2):145-153.

6. Braga F, Ferraro S, Mozzi R, Dolci A, Panteghini M. Biological variation of neuroendocrine tumor markers chromogranin A and neuron-specific enolase. Clin Biochem. 2013;46(1-2):148-151. 